Framework on crisis management during the pandemic of hotels in National Capital Region

\author{
Adem, Mark Daevid M. \\ Lyceum of the Philippines University-Batangas, Philippines (mmadem@tua.edu.ph) \\ Ylagan, Alex D. \\ Lyceum of the Philippines University-Batangas, Philippines (apylagan@lpubatangas.edu.ph)
}

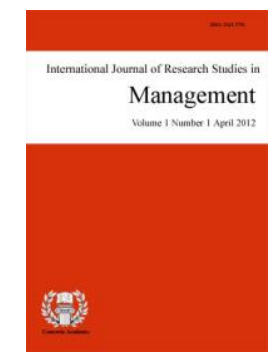

ISSN: $2243-7770$ Online ISSN: 2243-7789

OPEN ACCESS

\title{
Abstract
}

The COVID-19 pandemic has sparked a massive shift in the hotel industry. Businesses are seeking to adapt their operations to the current unpredictable environment. This study focused on the hotel's crisis management in terms of hotel management, implementation of health and safety protocols, and level of guest satisfaction. It assessed the different DOT-accredited establishments that served as staycation hotels during the COVID19 pandemic in the National Capital Region as the foundation for the proposed framework on crisis management. A descriptive-quantitative research design was utilized in the study, with 389 guests from 15 staycation hotels serving as participants. Test of differences and relationships to satisfy the requirements of the objectives of this investigation were conducted. Results revealed that there is a significant difference exists in terms of health and safety protocols of the hotels specifically the area of reception and concierge. The male respondents have significantly higher rates of observation than female respondents. There is also a significant difference in the implementation of health and safety protocols in terms of guest handling policies based on the responses of the hotel guests. The result showed that hotel guests who have visited at least one hotel have significantly higher observations on the implementation of health and safety protocols in their rooms, housekeeping, and reception and concierge compared to those who have visited two or more hotels. There is a significant positive moderate relationship across the three major variables: Hotel Management, Health and Safety Protocols, and Guest Satisfaction. A Pandemic Framework on Crisis Management of Hotels in the National Capital Region was proposed.

Keywords: crisis management, hotel management, health and safety protocols, customer satisfaction, framework 


\section{Framework on crisis management during the pandemic of hotels in National Capital Region}

\section{Introduction}

Tourism is an important segment for the economy of the Philippines. It is accounted for providing many opportunities as manifested from the improved infrastructures, accessibility, health and hygiene, and promotional marketing strategies. However, with the Covid-19 outbreak, the vast value-chain in social, political, and environmental including those related to Tourism sector have been greatly affected. It created havoc on the global travel economy and spread rapidly across the globe at the beginning of 2020. With concerns related to health and safety, many hospitality and tourism businesses have temporarily stopped their operations, while some have permanently closed and declared bankruptcy across the globe. In addition, mobilization was deeply affected as health and safety concerns increased, which caused a decrease in the number of customers visiting tourist attractions and guests staying in the hotels for business, leisure, or family vacation for fear of getting infected by the virus. The researcher reviewed the STR hospitality data analytics from the last quarter of 2019 until the last quarter of 2020 and found significant impact in terms of the hotel guest's check-in. The comparison from the previous year's data report showed a decline in terms of hotel demand or guests visiting the hotels in NCR.

Tourism revenues are expected to decline in 2020 as a result of the Covid-19 Pandemic. Overall, it cut world GDP to 1.5 percent from 2.8 percent (UNWTO, 2020). In 2019, the tourism and travel industry shared 12.7 percent of the Philippine's GDP. As a result of effective travel and tourist legislation, millions of international visitors visit each year. Tourist arrivals in the Philippines plummeted by $73 \%$ in the first seven months of 2020 , reaching 1.3 million visits, according to a report from the Philippines News Agency (2020).

In the last two years since 2019 December, hotels in NCR have shown resilience and have pivoted their strategies to combat the Covid-19 pandemic. Hotels, through their respective management, have developed ways to augment the spread of the virus. Government support and established policies initiated by the Philippines Department of Tourism are now implemented, ensuring the health and safety of guests in the accommodation establishments. Despite the Covid-19 pandemic, 15 hotels in NCR submitted to DOT'S accreditation qualifying as staycation hotels.

This study determined the pandemic framework on crisis management of hotels in National Capital Region. Studies on tourism and hospitality industry crisis management have made significant contributions to the sector in lessons learned from the crisis, providing context, analysis, and synthesis of elements that drove the development of the problem and the organizational response. However, few share information on how hotel organizations seek to manage and respond to crises proactively, specifically in the case of the National Capital Region, Philippines.

The researcher, as a member of the academe in hospitality and tourism management education, sees the importance of this study to the future of the hotel industry. Hotel industry provides countless opportunities to hospitality and tourism students and professionals. It provides exposures and prospects, offering them with exciting career, and partner in improving the quality of life as well as the economy. In the light of this pandemic, this study aimed to inform the members of the academe, future researchers, and hotel stakeholders on how hotels in NCR serving as staycation hotels are managing the crisis as assessed and observed by the hotel guests.

According to Zech (2016), Crisis Management has three phases these are pre-crisis phase, crisis phase, and post-crisis phase. In pre-crisis phase, this is where the organization plan the preventive measures, signal detection of the crisis, and the preventive preparation. While crisis phase is the utilization of crisis management 
plan, identification of the trigger crisis, event of the crisis, and where the organization response to the crisis. And lastly, the post-crisis phase is where the post-crisis evaluation is conducted, actions after operations have returned to normal

In this study, the crisis management of hotels in the National Capital Region was determined during the crisis phase only. The researcher determined the crisis management of the hotel in terms of their hotel management, assess the implementation of health and safety protocols as mandated by the government agencies, and determined the level of guest satisfaction of the hotel guest in the new normal set-up during the Covid-19 Pandemic.

To draw a pandemic framework on crisis management of hotels in NCR in the context of new normal, the variables used in the survey instrument of the conducted studies and policies were adopted. In the study of Francisco et al. (2020), the authors developed a competency scale that helped determine New Normal Leadership or Situational Leadership. Situational Leadership can adapt to the present situations, effective instructional decision-maker, good planner, vigilant, and initiator. Based on the findings of Francisco et al. (2020), New Normal Leadership has the capacity for adaptability, decision-making, planning, and implementation. In this study, the researcher used the competency scale created by Francisco et al. (2020), with consent to the original authors, transitioning from the Leadership competency scale to the Hotel Management competency scale. Thus, variable 1 of the study is called Hotel Management. The hotel, through their management, will be assessed based on their adaptability, decision-making, and planning and implementation in the new normal. Hidalgo et al. (2022) claim that labor policies have a greater impact on the likelihood of hotel activity recovery, particularly plans for temporary employment regulations, innovation and differentiation strategies, reorientation to closer markets, and obtaining information from official sources to ensure its accuracy. In addition, government initiatives that assist businesses in improving their financial situation can aid in the revival of hotels.

For Variable 2 of the study, the researcher adopted variables from DOT's Implementation of Health and Safety Protocols for accommodation establishments. This study limited the assessment to three specific protocols, such as guest handling policy, reception \& concierge, and rooms \& housekeeping. To control the impact of COVID-19, according to an OECD study (2020), each level of government in different states relies on the other for policy and service formation and execution in a variety of areas. Simultaneously, the effectiveness of policies will be heavily contingent on the ability of subnational governments to execute solutions. Trust among citizens can help guarantee that containment measures are followed and that "virus fatigue" is minimized.

And, for variable 3 of the study, the researcher adopted the variables from the study of Mercado (2021), assessing the level of Guest Satisfaction in terms of hotel facilities, amenities, and customer service. According to Chang et al. (2009), management that focuses on customer satisfaction can increase loyalty and help the company develop a positive image. Conversely, a management style that ignores customer satisfaction risks generating a negative public image for the company and may lower earnings. Furthermore, sustaining client happiness is critical to the company's product and service quality.

\subsection{Objectives of the study}

This study determined the crisis management of the hotels in the National Capital Region (NCR) in the New Normal. More specifically, it described the demographic profile of the respondents in terms of age, sex, civil status, highest educational attainment, frequency of hotel stay before pandemic, frequency of hotel stay during pandemic (March-Present), purpose of stay in hotel; number of hotels visited; which of the DOT Accredited Hotels did the respondents stay for staycation; it determined the Hotel Management in the New Normal in terms of adaptability; decision-making, planning \& implementation; it assessed the level of hotel implementation in managing health and safety protocols due to pandemic in terms of guest handling policy, reception and concierge, rooms and housekeeping; it determined the level of guest satisfaction in terms of hotel facilities, amenities, customer service; tested the significant difference on the responses when grouped according to profile; tested 
significant relationship on the variables such as hotel management, health and safety protocols, and guest satisfaction. And lastly, based on the result of the study, it prepared a framework on crisis management of hotels in NCR.

\section{Methods}

Research Design - This study used descriptive-quantitative research method and design. Test of differences and relationships were determined to satisfy the requirements of the objectives of this investigation. The researcher used triangulation of variables to investigate the significant relationship of the private sectors like hotel in terms of managing the hotel, government interventions through the implementation of the mandated health and safety protocols for accommodation establishments, and hotel guests in terms of guest satisfaction. According to Shuttleworth (2008), "descriptive research is a scientific method which involves observing and describing the behavior of a subject without influencing it in any way. It is also use when it is not possible to test and measure the large number of samples needed for more quantitative types of experimentation".

This study determined the Crisis Management of the 15 DOT Accredited Accommodation Establishments (Hotels) in the National Capital Region; specifically, the hotels were assessed and evaluated of the selected participants in terms their Hotel Management, Implementation of Health and Safety Protocols, and Guest Satisfaction using the modified survey questionnaire. Therefore, this study used a descriptive method which described the crisis management of the hotels as interpreted from the result of data gathering using the survey questionnaire. Survey research used quantitative research strategies such as numerically rated item questionnaires. Surveys are therefore often used in psychological and social research as it is frequently used to define and discover human behavior (Nassaji, 2015).

Participants of the Study - The participants of this study were the hotel guests who stayed overnight during the pandemic period beginning of March 2020 until June 2021. Hotel guests stayed among the 15 staycation hotels in the National Capital Regions located at Taguig City, Makati City, Paranaque City, Mandaluyong City, Pasig City, Makati City, and Pasay City. The list of the 15 staycation hotels can be found at the appendices of this study. The researcher used simple random sampling technique in which every member of the population has an equal chance of being selected into the study. Using Roasoft with margin of error of 5\% and $95 \%$ confidence level, a minimum of 300 respondents was computed based on the number of guest arrival/occupancy or a total of 984,942 room demands (STR, 2021) in the DOT Accredited Staycation Hotels during the Covid-19 pandemic starting January 2020 up to February 2021. Smith Travel Research or STR report was requested by the researcher himself from the STR SHARE Center Coordinator on April 15, 2021 via his personal email account. A total of 389 respondents participated in the survey.

Research Instrument - The researcher used modified survey questionnaire which is clustered into four parts. First part is on the profiling of the respondents in terms of age, sex, civil status, highest educational attainment, frequency of hotel stays before pandemic, frequency of hotel stays during pandemic (March-Present), purpose of stay in hotel; number of hotels visited; which of the DOT Accredited Hotels did the respondents stay for staycation. The second part is the assessment on hotel management in terms of adaptability, decision-making, planning and implementation (Francisco et al., 2020). The third part is the assessment of the respondents on the level of implementation of DOT's Health and Safety Protocols in terms of guest handling policy, reception and concierge, and room \& housekeeping (DOT, 2020). And lastly, the fourth part is the assessment on the level of guest satisfaction of the respondents in terms of hotel facilities, amenities, customer service (Mercado, 2021). The modified survey questionnaire was pilot tested, validated by forty individuals who at legal age, tech-savvy, have been in the hotels in NCR who volunteered validating the questionnaire. It was made using the google form communicated through their social media and email address. The researcher asked the participants of the pilot test for feedback to further refine of the instrument. After the validation, the questionnaire has undergone reliability test using Cronbach Alpha. The reliability test result for the assessment on the hotel management in the new normal obtained a Cronbach's alpha value of 0.868 which signifies that the questionnaire has a good

58 Consortia Academia Publishing (A Partner of Tourism Educators and Movers of the Philippines) 
internal consistency. Meanwhile, the instrument for identifying the level of implementation of the hotel on health and safety protocols obtained a Cronbach's alpha value of 0.949 which implies that the instrument has an excellent internal consistency as well as the instrument for guest satisfaction with 0.912 .

Data Gathering Procedure - Upon receiving the approval to conduct data gathering procedure from the adviser, the researcher immediately submitted a letter approved by the program dean of PhDIHTM / MIHTM address to the General Manager. Email addresses, contact numbers, hotel locations where the General Manager is currently assigned were collected through a telephone conversation conducted by the researcher with the hotel HR Manager / Director. The researcher has several follow-ups, for three consecutive weeks. Upon receiving feedbacks from the hotel, most of them declined for the physical or face to face conduct of data gathering procedure, due to the current climate in the hotel brought by the Covid19-Pandemic. Some managers did not allow either to extend help in terms of disseminating the questionnaire despite of providing QR code for contact less conduct of data gathering. However, managers gave their warm wishes for the completion of the study and the researcher understand where the sentiments and disapproval came from. Thus, the researcher consulted the adviser and statistician, to what possible way can the researcher accomplish the data gathering procedure. In their recommendations is to request for verbal endorsement from the Professional Associations such as Association of Administrators in Hospitality, Hotel and Restaurant Management Educational institutions (AAHRMEI), Hotel \& Restaurant Association of the Philippines (HRAP), and from the office of Department of Tourism (DOT). AAHRMEI immediately responded and supported my request to disseminate survey questionnaire as well as to HRAP with the assistance of AAHRMEI. On the side of DOT, since it was announced by the President that General Community Quarantine will be extended beginning March 12, 2021, the researcher did not receive any feedback from the office despite of many calls made. Security officer who received researcher calls mentioned that the staff would probably working from home.

For the last resources, the researcher decided to ask the assistance of the graduates where the researcher is currently working. The graduates / alumni are currently working in the accredited accommodation establishments, while some alumni are flying as flight attendants, some have relatives who stayed in the identified hotels, and the rest were randomly asked through the survey. It took two months before the target respondents were achieved. It was documented from April 12 up to June 12, 2021. At the end of data gathering procedure, it achieved a total of 389 volunteered responses. The questionnaire was distributed using random sampling technique. Since the researcher was not allowed to move around the city at the time of the study due to enhance community quarantine, the researcher utilized the google form to distribute the modified survey questionnaire. The researcher secured the discretion of the survey questionnaires.

Data Analysis - The data were gathered, tabulated, and analyzed using a statistical software called SPSS and the assistance and guidance of the research statistician. Frequency and Percentage, Weighted Mean and Ranking were used to tabulate the data under the demographic profile, to determine the crisis management of hotels through hotel management, implementation of health and safety protocols and guest satisfaction in the New Normal. Mann Whitney $U$ test was used to test the significant difference on sex and civil status and purpose of visit with two categories while Kruskal Wallis Test was used to test the significant difference for those profiles with three (3) or more categories. Meanwhile, Spearman rho was used to test the significant relationship across the three major variables. Non-parametric tests were used in the study because the result of Shapiro Wilk test for the three major variables are less than 0.01 , therefore the set of data is not normally distributed.

Ethical Consideration - In accordance with the Code of Ethics, the researcher ensured that all data collected from the respondents were consent- fully volunteered from the respondents. All the data gathered throughout the conduct of the study remained confidential and guaranteed that the procedures happened fair and were not of any bias to all the involved participants. Moreover, the researcher addressed the procedure about the writing the study in which participant's response served as their confirmation to participate in the study. The data were secured and private and avoiding any offensive, discriminatory, and other unacceptable language during the conduct of survey and interview. The researcher has communicated through email the authors of three (3) studies 
Adem, M. D. M., \& Ylagan, A. D.

in which the chosen variables were adopted from, researcher and authors where thru the text messaging. The researcher made a letter of consent and sent thru their email account in which content was to ask permission to use and adopt their developed questionnaire. Prior to the conduct of the survey, the respondents were asked to read the letter of consent attached to the form pertaining to their voluntary participation in the data gathering procedure. The response of the respondents signifies the approval and willingness of the respondents to join in the conduct of the survey. The study strictly followed the RA 10173 or the Data Privacy Act of 2012 which states, "to protect the fundamental human right to privacy of communication while ensuring free flow of information to promote innovation and growth [and] the [State's] inherent obligation to ensure that personal information in information and communications systems in government and in the private sector are secured and protected". Data cannot be retrieved without the consent of the respondents (ECCI, 2021).

\section{Results and Discussion}

\section{Table 1}

Demographic Profile of the Respondents

\begin{tabular}{|c|c|c|c|}
\hline Profile & Category & Frequency & Percent \\
\hline \multirow{4}{*}{ Age } & $21 \&$ Below & 26 & 6.7 \\
\hline & $22-37$ & 307 & 78.9 \\
\hline & $38-53$ & 51 & 13.1 \\
\hline & $54-72$ & 5 & 1.3 \\
\hline \multirow[t]{2}{*}{ Sex } & Male & 142 & 36.5 \\
\hline & Female & 247 & 63.5 \\
\hline \multirow[t]{2}{*}{ Civil status } & Single & 227 & 58.4 \\
\hline & Married & 162 & 41.6 \\
\hline \multirow[t]{4}{*}{ Educational Attainment } & HS & 32 & 8.2 \\
\hline & Bachelor & 302 & 77.6 \\
\hline & Master & 41 & 10.5 \\
\hline & Doctor & 14 & 3.6 \\
\hline \multirow[t]{4}{*}{ Frequency of hotel stay before pandemic } & Once & 100 & 25.7 \\
\hline & Twice & 157 & 40.4 \\
\hline & Thrice & 64 & 16.5 \\
\hline & Four Times & 68 & 17.5 \\
\hline \multirow[t]{4}{*}{ Frequency of hotel stay during pandemic } & Once & 339 & 87.1 \\
\hline & Twice & 6 & 1.5 \\
\hline & Thrice & 35 & 9.0 \\
\hline & Four Times & 9 & 2.3 \\
\hline \multirow[t]{2}{*}{ Purpose } & Holiday & 355 & 91.3 \\
\hline & Business & 34 & 8.7 \\
\hline \multirow{6}{*}{ Number of Hotels Visited } & 1 & 284 & 73 \\
\hline & 2 & 75 & 19.3 \\
\hline & 3 & 17 & 4.4 \\
\hline & 4 & 10 & 2.6 \\
\hline & 5 & 0 & 0 \\
\hline & 6 & 3 & .8 \\
\hline \multirow[t]{14}{*}{ DOT Accredited Hotels Visited } & Hotel 1 & 30 & 7.71 \\
\hline & Hotel 3 & 79 & 20.3 \\
\hline & Hotel 4 & 21 & 5.4 \\
\hline & Hotel 5 & 59 & 15.2 \\
\hline & Hotel 6 & 31 & 7.97 \\
\hline & Hotel 7 & 37 & 9.51 \\
\hline & Hotel 8 & 33 & 8.48 \\
\hline & Hotel 9 & 11 & 2.83 \\
\hline & Hotel 10 & 19 & 4.88 \\
\hline & Hotel 11 & 42 & 10.8 \\
\hline & Hotel 12 & 41 & 10.5 \\
\hline & Hotel 13 & 20 & 5.14 \\
\hline & Hotel 14 & 26 & 6.68 \\
\hline & Hotel 15 & 30 & 7.71 \\
\hline
\end{tabular}

Table 1 presents the demographic profile of the respondents, revealing that most of the respondents are

60 Consortia Academia Publishing (A Partner of Tourism Educators and Movers of the Philippines) 
25-40 years old, female, single, bachelor's degree holders, who stayed at least twice in the hotel before the Covid-19 Pandemic and stayed in the hotel at least once during the Covid-19 Pandemic. In addition, most of the respondents stayed in the hotel for a holiday, have visited at least one hotel during the Covid-19 Pandemic. Most of the respondents stayed in a hotel located in Paranaque City, Manila.

The respondents of the study were categorized according to their age range by generation. Dimock (2021) president of Pew Research Center determined the generation names according to the year they were born and the age range they had. Those who were born between 1922 to 1927 with an age range of 94-99 are called the World War II Generation. Those born from 1928 to 1945 with an age range of 76-93 are called the Post War Generation. Those born between 1946 to 1954 with an age range of 67-75 are called the Boomer 1 generation. Those born from 1955 to 1964 (57-66) are called the Boomers II generation. Those born between 1965 to 1980 with an age range of 41-56 are called the Gen X generation. Those born between 1981 and 1996 with an age range of 25-40 is called the Millennial generation. Furthermore, those born between 1997 to 2012 with the age range of 9-24 are called the Gen Z. generation.

Based on the data presented, most of the respondents of this study are millennials with an age range of 25-40 years old. According to Ferries (2021), Millennials are the largest generation to date, accounting for 31.5 percent of the world's population of 7.7 billion people. This generation is estimated to have $\$ 200$ billion in spending power, a solid financial motive for travel companies to pay attention to them. They are changing the way people travel by emphasizing experiences and culture, traveling solo, making their itineraries, avoiding cheap stock content, and basing their decisions on social media or user-generated content. Furthermore, from research to booking, all these new travel trends are done immediately on their smartphone. As supported by the study of Sofronov (2018), millennials use technology to make savvy travel-buying decisions, primarily based on the perceived authenticity of the experience they are offered, having grown up with near-ubiquitous internet access and beginning their professional careers in the aftermath of a financial crisis. More than any other generation, millennials travel. Millennials travel the most of any generation. They take 35 days of vacation per year on average. They are defying the trend by increasing their annual travel spending, despite previous generations' intentions to be more frugal with their money. Authenticity, fulfillment, and sustainability are essential to millennial tourists. The result of the current study is also prevalent in the survey conducted by the Department of Tourism, depicting millennials as the primary group of travelers according to 2019 DOT Tourism Statistics (Aquino, 2021).

On the other hand, only $1.35 \%$, or only five respondents, belong to the Boomers I \& II group. According to Vogels (2019), Baby Boomers continue to lag Gen Xers and Millennials on most technology adoption metrics. Adoption rates for this cohort, on the other hand, have been steadily rising in recent years. Boomers, for example, are now significantly more likely to own a smartphone than they were in 2011 (68 percent in 2019 vs. 25 percent in 2011). Furthermore, despite technology barriers, Boomers typically research online to make sure they find the best products and services and the best price. Additionally, $84 \%$ of Boomers will use online services to book travel, so companies should consider online presence and reputation to appeal to this generation, too (Ferries, 2021).

The same table shows the frequency and percentage distribution of the respondents according to sex. The data presented above shows that $63.5 \%$ of the respondents are female, with a frequency of 247 , while $36.5 \%$ are male. Women consumers are now driving the global travel sector, according to Bond (2019). Women are earning more, spending more, and having a greater impact on the travel sector at all levels. Women make up $85 \%$ of all consumer purchases, which range from automobiles to health care. The majority of web marketing is done by women. The spending power of women is worth $\$ 15$ trillion. These figures represent a market that is twice as large as China and India's combined growth markets. Women are predicted to spend $\$ 125$ billion this year and make $80 \%$ of the decisions. Women are decision-makers, independent of who they travel with, who pays for the vacation, or where they go. Women make up $75 \%$ of individuals who go on cultural, adventure, or nature trips. In the last six years, the number of women-only travel companies has increased by 230 percent. The women's 
Adem, M. D. M., \& Ylagan, A. D.

market has a potential of almost $\$ 19$ trillion each year, with 67 million members. Women travel in a different way than males. In comparison to $72 \%$ of males, almost 87 percent of women say they go for the lovely scenery, added by Bond (2019).

However, according to Statistica.com (2020), the share of travel \& tourism users in 2020 by gender in the Philippines shows that 51.7 percent of travelers and users of tourism were male in 2020 . In comparison, 48.3 percent of users were female. The researcher posits that due to the existence of the coronavirus from early 2020 to the end of 2020, female travelers and tourism users will not take the risk of traveling because of COVID 19. However, they are very eager to do so. As humans, we have physiological needs such as food, clothing, shelter, and safety needs such as security, whether job, health, and safety (McLeod 2020). With the climate we humans are currently experiencing due to Covid19, the researcher posits that male travelers are risk-takers considering they need to travel either for work, business, or leisure. In addition, a male is expected to be the provider of the family or breadwinner of the family. In this regard, the researcher infers that hotel can offer a unique package that is gender neutral. Alternatively, offer packages depend on female or male guests' interests or preferences.

The table also shows the frequency and percentage distribution of the respondents based on their civil status. The data above shows that $58.4 \%$ of the respondents, with a frequency of 227 , are single, followed by $41.6 \%$ of the respondents, with a frequency of 162, are already married. According to the National Institute of Population and Social Security Research (retrieved as of 2021), 24\% of males in Japan had not married by the age of 50, while just $14 \%$ of women have. "I do not think I will be lonely even if I continue to live alone," said 48 percent of men, up 10 points from 1997, according to the 2015 National Fertility Survey (of unmarried men and women aged 18 to 34) who said they "do not want to get married yet." It's because they want to spend their money on themselves that they stay single in Japan. There is a prevalent misconception that marriage restricts a man's ability to spend money. This is in stark contrast to the fact that one of the benefits of marriage for women is "financial security".

Between 2018 and 2019, over 60,000 women traveled alone, according to Mittra (2020). Currently, 47\% of O.A.T passengers have registered as "solo," with women accounting for an incredible $83 \%$ of all solo travels. Tour organizers have discovered that the number of women traveling single greatly outnumbers the number of males. For every single male traveler, there are four female solo passengers. Single people are more sociable and more willing to reach out to others than married people, according to a 2016 study. Married persons, on the other hand, are more likely to isolate themselves. According to Sarkisian \& Gerstel (2015), single people are more likely to keep in touch with, help, and receive help from their parents, siblings, neighbors, and friends on a regular basis than married people. "Both men and women benefit from being single since it strengthens their social ties. "The same table shows the frequency and percentage distribution of the respondents according to their educational attainment. It indicated that $77.6 \%$ of the respondents with a frequency of 302 are bachelor's degree holders, 10.55 of the respondents with a frequency of 41 are master's degree holders, and $8.2 \%$ of the respondents with a frequency of 32 are at least High-School Degree holders. The least among the group, with 3.65 of the respondents with a frequency of 14 , are Doctorate Degree holders.

Earning a college degree, according to Loveless (2021), is all about expanding one's horizons in life. It prepares an individual to profession and adult life, both intellectually and socially. Career prospects such as higher-paying and higher-skilled professions are among the advantages of a college education, but studies have also shown that it improves general satisfaction and stability. According to the Average Salary Survey (2021), the annual wage in the Philippines is 855,463 PHP. The average salary is 335,513 PHP. According to the 3,078 salary surveys data, the results showed that in terms of gender, salaries aren't the same. The average wage for men is 1,082,174 PHP. A salary of 703,428 PHP is paid to women. Sports \& recreation, with an average salary of 2,203,844 PHP, and logistics, road, and railway, with an average income of 1,768,012 PHP, are the highest-paid professions. With a salary of 1,376,468 PHP, those with a master's degree have the highest education. With a salary of 1,282,812 PHP, a doctorate degree is the second highest paid educational level. Earnings are influenced by a variety of factors. A salary of $1,676,561$ PHP is paid to people with more than 20 years of experience.

62 Consortia Academia Publishing (A Partner of Tourism Educators and Movers of the Philippines) 
Employees with 16-20 years of experience receive 1,666,399 PHP.

The researcher posits that only a few doctoral degree holders responded to the study due to the profession and nature of the work they possess. Moreover, only a few have continued to take doctoral programs after finishing their master's degree program. Having a higher degree demands higher skills, and offers higher pay (Loveless, 2021). The table also shows the frequency and distribution of the respondents based on their frequency of hotel stays before the pandemic. The data indicated above that $40.45 \%$ of the respondents with a frequency of 157 visited hotels at least twice, followed by $25.7 \%$ of the respondents with a frequency of 100 visited hotels at least once. Meanwhile, $17.5 \%$ of the respondents, with a frequency of 68 , visited the hotel four times, and the least with $16.5 \%$ of the respondents, with a frequency of 64 , visited the hotel at least thrice before the pandemic. On average, each domestic traveler took two visits during the reference period, according to preliminary results from the HSDV 2016, which was jointly conducted by the Philippine Statistics Authority (PSA) and the Department of Tourism (DOT). On average, three out of every ten domestic tourists remained for five nights in the places they visited during their most recent trip. A little over $40 \%$ of them had remained for two or three nights or more. Three out of every four domestic travelers in the NCR were day visitors in the cities they visited. In terms of domestic passengers who travel for pleasure or holiday, the NCR was the most popular destination.

In 2019, approximately 46.3 million domestic travelers stayed in accommodation establishments in the Philippines (Statisca.com, June 2021). The same table shows the frequency and distribution of the respondents based on their frequency of hotel stays during a pandemic. The data indicated that $87.1 \%$ of the respondents, with a frequency of 339, visited the hotel at least once, followed by $9 \%$ of the respondents with a frequency of 35 visited the hotel thrice. While $2.3 \%$ of the respondents, with a frequency of 9 , visited the hotel four times, and the least with $1.5 \%$ of the respondents with a frequency of 6 visited the hotel twice.

The coronavirus pandemic continues to have an impact on the Philippine tourism industry, as demonstrated by a 73 percent decline in international visitor arrivals for the first seven months of 2020 compared to the same period last year, according to the Philippine News Agency (2020). From January to July 2020, 4,852,107 international tourists were registered, down from 4,852,107 in the same months of 2019. The researcher posits that due to the impact of the COVID19 pandemic and travel restrictions, beginning March 2020-December 2020 before the issuance of Guidelines on Health and Safety Protocols in Accommodation Establishments, as well as the announcement of the President last March 2020, hotel guests were also inhibited from socializing and attending the mass gathering. Thus, solo trips and hotel bookings were canceled or rescheduled.

The above table also shows the frequency and distribution of the respondents according to their purpose of visiting the hotel. The data indicated that $91.3 \%$ of the respondents, with a frequency of 355 , visited the hotel for holidays and leisure, followed by $8.7 \%$ of the respondents, with a frequency of 34 , who visited hotels for business purposes. According to early results of the $2016 \mathrm{HSDV}$, which was jointly carried out in collaboration with the Philippine Statistics Authority (PSA) and the Department of Tourism (DOT), about two-fifths of visitors from the United States aim to travel for pleasure or vacation. To put it in perspective, three out of ten people went to see friends or relatives, and $6 \%$ went on religious or pilgrimage vacations. President Rodrigo Roa Duterte, however, has approved the extension of the General Community Quarantine (GCQ) in the National Capital Region (NCR) from March 2021 to July 31, 2021, due to the status of Metro Manila. Until July 31, 2021, other parts of the Philippines will be subjected to a modified general community quarantine (MGCQ) (Rocamora, 2021).

Lastly, the same table shows the frequency and percentage distribution of the respondents based on the number of hotels they have visited. The data above shows that $20.3 \%$ of the respondents with a frequency of 79 visited Hotel 3 located in Paranaque City. Some of the respondents, with a frequency of 31 or $7.97 \%$, visited Hotel 6, located in Paranaque City. The least number of respondents, or 2.83\%, with a frequency of 11, visited Hotel 9 in Paranaque City. Hotel 3 is a venue that houses a hotel, a casino, and a retail mall all in one area, 
Adem, M. D. M., \& Ylagan, A. D.

giving visitors a wide range of activities to choose from. With opulent facilities, outstanding service, and vividly decorated rooms, Hotel 3 treats its visitors. From two world-class retreat spas to the breathtaking views of Manila Bay from your suite, a staycation here is synonymous with a lap of luxury.

The researcher posits that most of the respondents have experienced Hotel 3 during the covid19 pandemic. Despite the cost, they find happiness in the amenities and services that the hotel offers them. On the other hand, Hotel 9 Zen accommodations, though the least visited hotel by the respondents, gives peace and tranquility. Guests may enjoy a pleasant break with panoramic hotel views, comfortable beds, and a decor that ideally balances warmth and luxury. The researcher posits that the respondents during the conduct of the study, mostly visited Hotel 3, while the least number of respondents visited Hotel 9 during the COVID19 pandemic.

Table 2

Summary of Hotel Management, Health and Safety Protocols, and Guests Satisfaction

\begin{tabular}{llllll}
\hline Hotel Management & CM & SD & VI & Level & Rank \\
Adaptability & 3.46 & 0.46 & S & High & 3 \\
Decision-Making & 3.52 & 0.50 & HS & Very High & 2 \\
Planning and Implementation & 3.51 & 0.46 & HS & Very High & 1 \\
Cluster Mean & 3.50 & 0.04 & HS & Very High & \\
\hline Health and Safety Protocols & & & & & \\
Rooms \& Housekeeping & 3.59 & 0.45 & HI & Very High & 1 \\
Reception and Concierge & 3.54 & 0.39 & HI & Very High & 2 \\
Guest Handling Policy & 3.45 & 0.45 & I & High & 3 \\
Cluster Mean & 3.53 & 0.40 & HI & Very High & \\
\hline Guest Satisfaction & & & & & \\
Facilities & 3.67 & 0.39 & HS & Very High & 1 \\
Amenities & 3.48 & 0.48 & S & High & 3 \\
Customer Service & 3.63 & 0.38 & HS & Very High & 2 \\
Cluster Mean & 3.59 & 0.37 & HS & Very High & \\
Scale: $3.50-4.00:$ Very High; 2.50-3.49: High; 1.50-2.49; Low; 1.00-1.49: Very Low & &
\end{tabular}

Scale: 3.50-4.00: Very High; 2.50-3.49: High; 1.50-2.49; Low; 1.00-1.49: Very Low

Table 2 shows the summary of Hotel Management, Health and Safety Protocols, and Guest Satisfaction in terms of cluster meaning, verbal interpretation, highest and lowest ranking, and highest and lowest extent of the three (3) main variables. Variable 1-Hotel Management with a summary cluster mean of 3.50 (0.040), verbally interpreted as highly satisfied, while the level of extent is very high; and lastly, Variable 3-Guest Satisfaction with a summary cluster mean of $3.59(\mathrm{SD}=0.37)$, verbally interpreted as highly implemented, while the level of extent is very high.

The table shows the summary of cluster meaning, verbal interpretation, highest and lowest ranking, highest and lowest extent, and highest and lowest ranking of Variable 1 Hotel Management. Under the hotel's management, decision-making ranked 1 , with the highest cluster mean of $3.52(\mathrm{SD}=0.50)$, verbally interpreted as highly satisfied, and the level of extent is very high. This can be interpreted in terms of how the hotel gave importance to their guests through the information they shared. The guests feel valued despite the crisis, and their needs and wants are given enough attention by understanding that every decision that the hotel makes in consideration of the current climate of the hotel amidst the crisis (Alexander et al., 2020).

On the other hand, ranked 3 under Variable 1 Hotel Management, adaptability got the lowest rank with the lowest cluster mean of 3.46 ( $\mathrm{SD}=0.46$ ), verbally interpreted as satisfied, yet the level of extent is still high. This can be interpreted in terms of how the hotel embraces the challenges brought by the crisis, as observed by the guests, to grow and advance. Crises might slow down the mobility of the hotel to grow and be competitive at the same time. Hotel management is also having difficulties applying new ideas or strategies to manage and promote the business (Rodríguez-Antón, \& Alonso-Almeida, 2020). However, hotels' and hotel employees' business resiliency, the support of the government through mandated policies, and guest trust are what keeps the business going (ILO, 2010; DOT 2020).

The table also shows the summary of cluster meaning, verbal interpretation, highest and lowest ranking, 
highest and lowest extent, and highest and lowest ranking of Variable 2 Implementation of Health and Safety Protocols. Despite ranking first with the highest cluster mean of 3.59 ( $\mathrm{SD}=0.45)$, the guest handling policy is verbally interpreted as highly implemented, with a very high level of extent. This can be interpreted to mean that DOT's guest handling policy is highly implemented by the hotels to ensure a healthy and safe stay for the guests (DOT, 2020).

On the other hand, ranked 3 under Variable 2 Implementation of Health and Safety Protocol, rooms \& housekeeping got the lowest rank with the lowest cluster mean of 3.45 ( $\mathrm{SD}=0.45$ ), verbally interpreted as implemented, yet the level of extent is implemented. This can be interpreted that the hotel, in terms of implementing DOT's health and safety protocols, particularly the room and housekeeping, should always and equally follow the protocols. Although it is implemented, guidelines specifically describe the utilization of single up to double room occupancy to accommodate guests, $1-2$ meters between the beds, a separate trash bag or bin for used PPE, standard disinfection, and proper washing of used linen and washable items should be strictly followed to provide a high level of trust among the guests to make sure that health and safety will not be compromised (DOT, 2020).

The table shows the summary of cluster meaning, verbal interpretation, highest and lowest ranking, highest and lowest extent, and highest and lowest ranking of Variable 3 Guest Satisfaction. Despite ranking first with the highest cluster mean of 3.67 ( $\mathrm{SD}=0.39$ ), guest facilities were verbally interpreted as highly satisfied, and the level of extent is very high. Amidst the COVID19 pandemic, public areas, common areas, or facilities of the hotel ensure a high level of satisfaction. To encourage and gain trust from guests, hotel facilities should be safe and clean all the time (Shin \& Kang, Oct. 2020) and available with proper observation of the protocols set by the DOT and DOH for hotels to strictly follow (DOT, 2020).

On the other hand, ranked 3 under Variable 3 Guest Satisfaction, amenities got the lowest rank with the lowest cluster mean of 3.48 ( $\mathrm{SD}=0.48$ ), verbally interpreted as satisfied, yet the level of extent is high. Hotel in terms of guest satisfaction through the utilization of Wi-Fi connections, appropriate timing for room service, and the provisions of ATM machines near the hotel can be improved in terms of guest satisfaction as these are some attributes influencing guest satisfaction. To keep the hotel as a place for staycations, convenience and accessibility to hotel amenities should be given enough attention and consideration. Although these traits may alter over time, according to Jang et al. (2018), the fluctuations in attribute relevance suggest that hotel management should regularly investigate attributes that become more (or less) important to avoid underinvestment (overinvestment).

\section{Table 3}

Correlation Matrix Across Hotel Management, Health and Safety Protocols and Guests Satisfaction

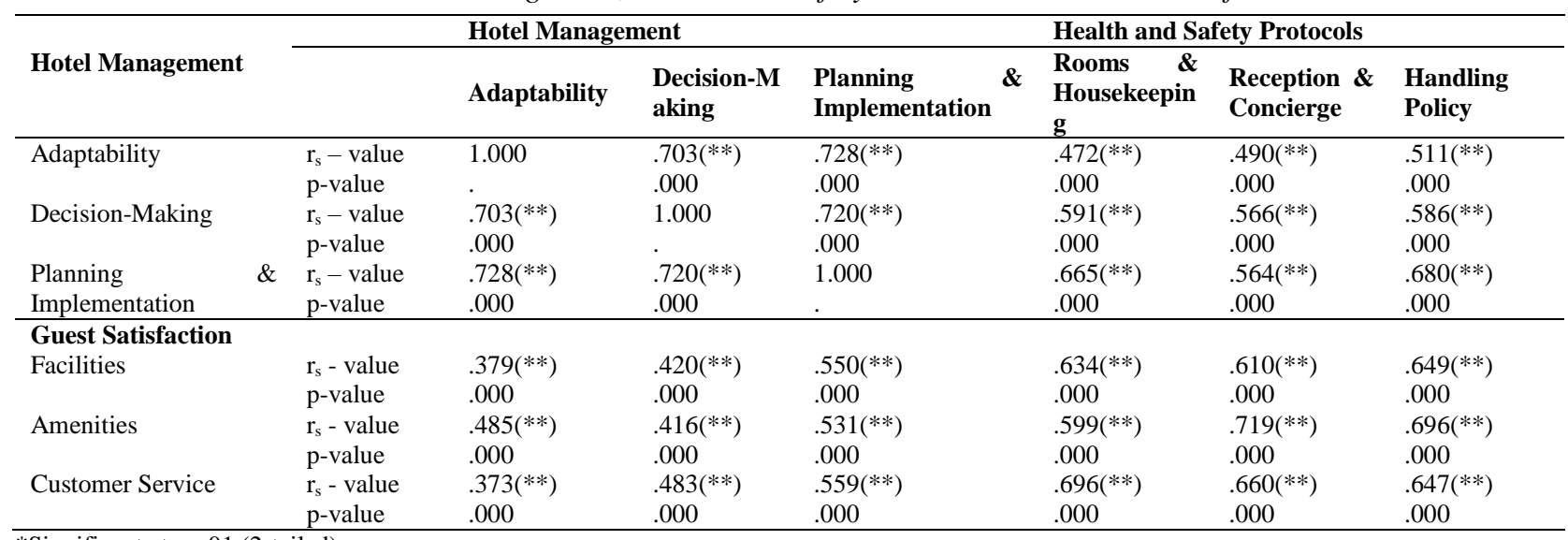

*Significant at $\mathrm{p}<.01$ (2-tailed)

Table 3 reveals the correlation matrix across the hotel's management in the new normal, health and safety protocols, and guest satisfaction. There is a significant positive moderate relationship across the three major 
variables: Hotel Management, Health and Safety Protocols, and Guest Satisfaction as denoted by the computed p-values of less than 0.01 alpha level.

This signifies that those respondents with higher satisfaction as observed through the hotel management in the new normal in terms of adaptability, decision-making, and planning \& implementation are also those respondents with higher responses to the implementation of the health and safety protocols mandated by the government agency in terms of room and housekeeping, reception \& concierge, and guest handling policy, as well as those respondents with a higher level of guest satisfaction in terms of facilities, amenities, customer service. Therefore, if the respondents have a lower level of satisfaction or assessment in terms of hotel management, it can be assumed that the health and safety protocols and guest satisfaction could also result from having a low level of satisfaction. This can be interpreted to mean that in times of crisis at large, like the COVID19 pandemic, the private sector, government, and community are dependent to one another. For hotels to sustain their business in times of global or local crisis, the government should take part of the solution. The policy has been seen as effective in ensuring business continuity among the hotels in the NCR. More so, since the hotel measures the quality of the service, guests give significant purpose to the existence of the hotel. Therefore, the recovery of the hotel industry from the aftermath of the COVID19 Pandemic can only be realized through proper management of the hotel, following government policy mandated by the government, ensuring the health and safety of the people, and lastly, understanding the wants and needs of the guests could lead to a higher level of satisfaction. needed.

According to Mones and Cruz (2015), a tourist crisis is a critical or decisive moment or position; a turning point; an unstable state in political, social, or economic matters. This circumstance necessitates that manager be prepared to confront and handle it without causing significant harm to the business, whether physically or in terms of image and reputation. Such preparation is contingent on the level of perception of the possibility of a crisis arising.

The tourism industry needs credible steps from governments to promote market trust and limit the risk of this virus (Assaf \& Scruderi, 2020). In general, amid this crises, governments' roles should change with time. In addition to hotel actions in combating Covid-19 and business continuity, as well as implementing government protocols in the hotel industry, the Shimanovic (2021) study revealed that during the Covid-19 pandemic, there was a shift in the importance of hotel choice and satisfaction attributes in terms of changes made in the hotel industry. According to their research, a guest's decision to choose a hotel has a higher impact on their decision than before, and they examine it before making a hotel reservation. Furthermore, while guests are in a hotel, safety is now an inherent part.

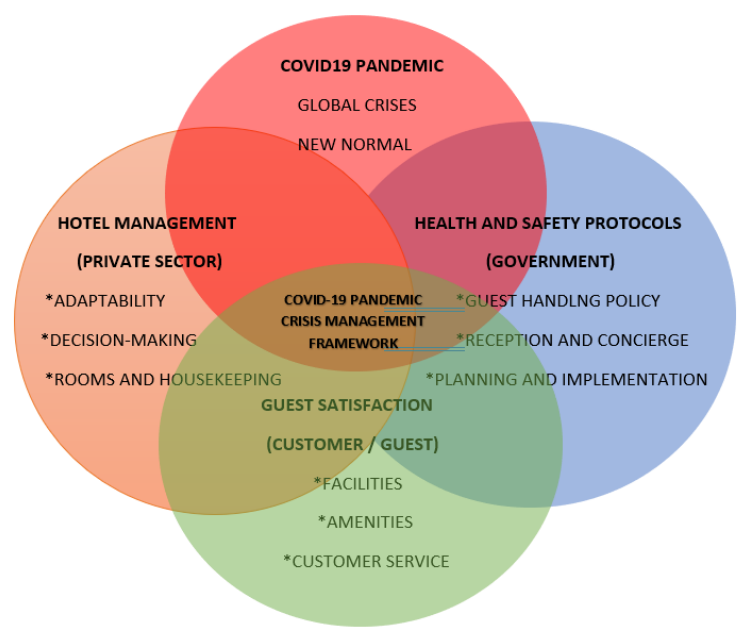

Figure 1. Framework on Crisis Management during the pandemic of the hotels in national capital region 
Model Description - Based on the findings of the study, a crisis management of selected hotels during the pandemic in the National Capital Region is hereby proposed. The framework was derived from the concept of Venn Diagram introduced by John Venn, an English Logician and Philosopher. Adem's Framework depicts the relations of inclusions of the three major variables as affected by the Covid-19 Pandemic that brought the hotel industry in the state of new normal. As shown in the diagram, the circles are intersecting which shows the positive moderate relationship of the variables.

Red Bubble represents the COVID-19 Pandemic. According to the reviewed literature, unexpected phenomena have had a huge global impact in economic, social, and environmental aspects. The intensity or level of impact has reached its peak even in the hospitality and tourism industries. It puts everything at a halt and reduces the mobility to engage with the people (guests or customers) in the community. This situation is not what every human has been accustomed to before. Now it is regarded as the new normal. A new "normal" is defined as a current situation, social custom, etc., that is different from what has been experienced or done before but is expected to become usual or typical.

Orange Bubble represents the private sector. Hotel owners have been greatly affected by the ongoing crisis brought by the COVID19 Pandemic. Many hotels have pivoted strategies to continue the operation. On a sad note, many hotels have closed either temporarily or permanently. For those hotels that chose to continue their operations, it has been a great challenge to survive. Many people see COVID19 as destructive, but others see it as an opportunity. In this study, the researcher assessed the management of hotels as allowed by the DOT to operate in the new normal in terms of their adaptability, decision-making and planning and implementation.

Green Bubble represents the guests, customers, tourists, and frequent travelers. They are highly regarded for their loyalty and continued support of the hospitality and tourism industries. Connecting with our customers is one way to measure customer satisfaction, a real-time insight that could help determine the position of the business. Through customer feedback, whether positive or negative, the management has an opportunity to improve or develop new products and services. With the on-going crisis, having guests in the hotel is greatly needed to continue and sustain its operation. In this study, the researcher determined the level of guest satisfaction in terms of facilities, amenities, and customer service in the New Normal.

Blue Bubble represents the government, policy makers, and authorities. They play a vital role in the lives of the community and in business. With the on-going phenomena brought by the COVID-19 pandemic, government policies and travel restrictions serve as preventive measures to stop or mitigate the spread of the virus at large. Through government initiative, a guideline on health and safety protocols for accommodation establishments was created to help the hotel business continue its operations. In this unprecedented time, it is undeniable that government, policy makers, and authorities have been great instruments to get business going. To determine the extent of mandated protocols, the study assessed the level of implementation of health and safety protocols of the hotel in the New Normal.

Core Bubble represents the Hotel Pandemic Framework on Crisis Management. The researcher posits that to determine the Framework on Crisis Management of Hotels in NCR, the impact of the crisis with its integration into hotel management (private sector), implementation of health and safety protocols (government), and guest satisfaction (community) should be assessed.

In times of a pandemic, the quality of hotel management can be expressed through the level of guest satisfaction as well as the proper implementation of health and safety protocols. The proper implementation of health and safety protocols is a manifestation of how hotel owners and managers follow the mandates of the government and directives of the Department of Health and Department of Tourism for the welfare of their guests. This is connected to the efficient hotel management in establishing concrete plans on how to address the challenges of the current situation while guest satisfaction is the result of the actual performance of the hotels.

From the result of the study, hotel management in terms of adaptability to the changing needs of the 
community and the environment helps the hotel managers adjust during a pandemic when it comes to following the IATF issuances and other local and city ordinances. Meanwhile, planning and implementation is another important component of crises management where everyone is involved in identifying the current situation and finding alternative solutions as the basis for wise and sound decision making.

In the course of the Covid-19 pandemic, hotel choice and satisfaction were attributed to health and safety in the hotel industry, which is a more important and vital part of hotel management and operations. To give guests a sense of security while traveling, hotels must adapt safety measures. In order to gain trust in the midst of the Covid-19 Pandemic, hotels should communicate the newly implemented safety measures to guests prior to their booking of a hotel room (Schimanovich, 2021). Throughout COVID-19, service quality, whether in terms of amenities, facilities, or customer service, influenced tourists' perceptions of hotel performance and, as a result, tourists' satisfaction. The operation of tourism and hospitality businesses should take into account the current crisis brought on by the Covid-19 Pandemic when making long-term plans (Nilashi et al., 2021).

Crisis management failures can be minimized by a coordinated response from all levels of government. To avoid coordination failures and disjointed responses that can lead to collective risk, horizontal coordination is essential. No single government, or government level, can meet the demands of crisis management on its own. Given the scope and magnitude of the COVID-19 crisis, all levels of government are being challenged to strengthen their partnerships - with each other, with the private and third sectors, and with citizens. The likelihood of an effective support program increases if priorities are mutually identified and agreed upon, and initiatives are designed with sufficient information exchanged between developers and implementers. While coordination is required, it also necessitates a clear delineation of roles and responsibilities, as well as mutual respect in the short, medium, and long term. Rapid mobilization of necessary public, private, and third-sector actors can aid governments in more effectively responding to crises (OECD, 2020).

\section{Conclusions and recommendations}

Most of the respondents age is from 25-40 years old, belonging to the group of millennials, female, single, bachelor's degree holder, stayed in the hotel before the pandemic at least twice a year, stayed in the hotel during the pandemic at least once (March 2020-June 2021); the purpose of visit to hotel is for holiday, number of hotels visited during the pandemic at least one, and Hotel 3 is the most visited hotel among the 15 accredited hotels for staycation. The hotel's management has a good sense of decision-making, followed by planning and implementation strategies, and lastly, adaptability in times of crisis as assessed by the hotel guests. Hotel guests are highly satisfied with the hotel management at the time of Pandemic Crisis in the New Normal. The staycation hotels in the NCR are compliant in the implementation of the DOT's health and safety protocols to mitigate the spread of the virus, specifically in the area of guests handling policy, reception and concierge, and rooms and housekeeping as determined by the hotel guests. Despite the COVID-19 Pandemic, the staycation hotels maintain high level of satisfaction among their guests in terms facilities, amenities, and customer service as perceived by hotel guests. There is a significant difference between the implementation of health and safety protocols in terms of rooms, housekeeping, and reception and concierge services from different staycation hotels. There is a significant positive moderate relationship across the three major variables: Hotel Management, Health and Safety Protocols, and Guest Satisfaction. ADEM'S Pandemic Framework on Crisis Management is proposed.

Hotels may consider the profile of the hotel guests and observe their behaviour to further improve their products and services in the future. Further recommended, to perform market segmentation of the last 3 generations such as Gen $\mathrm{X}, \mathrm{Y}, \& \mathrm{Z}$ exploring both the demographic and psychographic profile and compare it with pre-pandemic, during pandemic and post pandemic era. For the business continuity of the hotel, the management can be more adaptive to new technology, improve their flexibility and be innovative to cater the existing and future market with various requirements regardless of their situation. The hotel may continue observing government mandated protocols to ensure a healthy and safe stay in the hotels even Covid-19

68 Consortia Academia Publishing (A Partner of Tourism Educators and Movers of the Philippines) 
Pandemic is over and ensure all the hotel staffs are fully vaccinated to create a good impression to their future guests. To ensure a high level of guest satisfaction, the hotel may develop exiting products and services whether in terms of guest using hotel facilities, amenities, and customer service, that goes beyond guest expectations that can help persuade future guests. The hotel may also create a video advertisement that can be promoted in their social media accounts or website promoting a safe and healthy stay in the hotels capturing the various generations whether for business, leisure or family vacation. The hotel may conduct post pandemic organizational research to determine if the observation if this study has changed or improved in terms of significant relationships between the respondents' profile and variables. In terms of hiring employees, hotels may consider the resiliency of the person and his coping mechanism during Covid-19 Pandemic. For future researchers, this research may be adopted, or survey questionnaire can be modified, looking for more variables used in crisis management studies. Theory on Crisis Management can further review and explore on the usefulness of possible variables in conducting research. Qualitative and Quantitative research can be applied in designing their future research. Conducting interview with hotel managers can be a great help in understanding the nature and status of the hotel in the new normal. And lastly, the researcher recommends conducting a comparative study on crisis management during and post Covid-19 era.

\section{References}

Alexander, A., De Smet, A., \& Weiss, L., (2020). Decision making in uncertain times. McKinsey \& Company.com https://www.mckinsey.com/business-functions/organization/our-insights/decision-making-in-uncertain-t imes

Aquino, J. (2021 June 21). Quality Service Management: Incorporating the GUEST Technique. Podcast. Philippine Department of Tourism Webinar.

Assaf, A., \& Scruderi, R. (2020, June 12). COVID-19 and the recovery of the tourism industry. Sage Journals Tourism Economics, 26(5), 731-733. https://doi.org/10.1177/1354816620933712

Average Salary Survey.com (2021, June). Philippines Average Salary Survey 2021. https://www.averagesalarysurvey.com/philippines.

Bond, M. (2019). Women Travel Statistics from Women Travel Expert. Guystraveler.com. https://gutsytraveler.com/women-travel-statistics-women-travel-expert/

Chang, H.H., Wang, Y. H. \& Yang, W.Y. (2009). The impact of e-service quality, customer satisfaction and loyalty on e-marketing: Moderating effect of perceived value. Total Quality Management \& Business Excellence, 20(4), 423-443. https://doi.org/10.1080/14783360902781923v

Dimock, M. (2019, Jan 17). Where Millennials end and Generation Z begins. Pew Research Center. org. https://www.pewresearch.org/fact-tank/2019/01/17/where-millennials-end-and-generation-z-begins/

DOT. (2020, May 22). Health and safety guidelines governing the operations of accommodation establishments under the new normal. Tourism. http://www.tourism.gov.ph/healthandsafetyguidelinesnewnormal

ECCI, (2012), A Summary of RA No. 10173 or the Data Privacy Act of 2012. Ecci.com. https://eccinternational.com/ra-10173-data-privacy-summary/

Ferries, C. (2021). 60+ Millennial Travel Statistics \& Trends (2020-2021). Condorferries.co.uk. https://www.condorferries.co.uk/millennials-travel-statistics-trends

Francisco, C.D.C., Sagcal, N.C., \& Nuqui, A. (2020, October). Development and Validation of New Normal Leadership Competency Scale: An Offshoot of Emerging Type of Situational Leadership in the New Normal Education. International Journal of Academic Multidisciplinary Research, 4(11), 51-55.

Hidalgo A, Martín-Barroso D, Nuñez-Serrano JA, Turrión J, Velázquez FJ. (2022). Does hotel management matter to overcoming the COVID-19 crisis? The Spanish case. Tour Management. DOI. https://doi.org/10.1016/j.tourman.2021.104395

ILO. (2020). Developments and Challenges in the Hospitality and Tourism Sector. Retrieve from International Labor Organization-Geneva https://www.ilo.org/wcmsp5/groups/public/---ed_dialogue/

Loveless, B. (2021). Benefits of Earning a College Degree. Educationcorner.com. 
Adem, M. D. M., \& Ylagan, A. D.

https://www.educationcorner.com/benefit-of-earning-a-college-degree.html

McLeod, S. (2020). Maslow's Hierarchy of Needs. Simplypsychology.org. https://www.simplypsychology.org/maslow.html

Mercado, F. (2021). Customers' safety and security in selected resorts in Oriental Mindoro: Basis For An Action Plan. Pdf. Thesis

Mittra, P. (2020). Going solo: Freedom, self-confidence and experience are the biggest travel takeaways, say women. Indian express.com.

https://indianexpress.com/article/lifestyle/destination-of-the-week/going-solo-freedom-experience-selfconfidence-biggest-takeaways-say-women-6270938/

Mones, R.A. \& Cruz, C.G., (2015). The development of a crisis management program in The Philippine Hospitality and Tourism Industry. http://doi.org/10.13140/RG.2.1.4859.5042

Nassaji, H. (2015). Qualitative and descriptive research: Data type versus data analysis. Language Teaching Research. https://doi.org/10.1177/1362168815572747

Nilashi, M., Abumalloh, R., Minaei-Bidgoli, B., Abdu Zogaan, W., Alhargan, A., Mohd, S., Syed Azhar, S., Asadi, S., \& Samad, S., (2022). Revealing travellers' satisfaction during COVID-19 outbreak: Moderating role of service quality. Journal of Retailing and Consumer Services, 102783, 64. https://doi.org/10.1016/J.JRETCONSER.2021.102783

NIPSSR. (2017). The 15th Japanese National Fertility Survey. Ipss.go.jp Retrieved from. http://www.ipss.go.jp/ps-doukou/e/doukou15/Nfs15_gaiyoEng.html

OECD. (2020, Nov 10). OECD Policy Responses to Coronavirus (COVID-19) - The territorial impact of COVID-19: Managing the crisis across levels of government. Retrieved from: OECD. Org. https://www.oecd.org/coronavirus/policy-responses/the-territorial-impact-of-covid-19-managing-the-cri sis-across-levels-of-government-d3e314e1/

Rocamora, J.A.L. (2021, Jul 15). GCQ status in NCR extended until July 31. Pcco.gov.ph. https://pcoo.gov.ph/news_releases/gcq-status-in-ncr-extended-until-july-31/

Rodríguez-Antón, J. M., \& Alonso-Almeida, M. D. M. (2020). COVID-19 impacts and recovery strategies: The case of the hospitality industry in Spain. Sustainability, 12(20), 8599.

https://doi.org/10.3390/su12208599

Sarkisian, N., \& Gerstel, N. (2015, Aug 3). Does singlehood isolate or integrate? Examining the link between marital status and ties to kin, friends, and neighbors. Journal of Social and Personal Relationship. 33.3.361-384. https://doi.org/10.1177/0265407515597564

Shimanovich, A. (2021). The shift in significance of hotel choice and satisfaction attributes during the Covid-19 pandemic in respect of changes made in the hotel industry, Retrieved from: https://www.modul.ac.at/uploads/files/Theses/Bachelor/Undergrad_2021/

Shin, H., \& Kang, J. (2020 Oct). Reducing perceived health risk to attract hotel customers in the COVID-19 pandemic era: Focused on technology innovation for social distancing and cleanliness. Int J Hosp Management. https://di.org/10.1016/j.ijhm.2020.102664

Shuttleworth, M. (2008, Sep. 26). Descriptive Research Design. Explorable.com. https://explorable.com/descriptive-research-design

Sofronov, B. (2018). Millennials: A new trend for the tourism industry. Annals of Spiru Haret University, Economic Series, Universitatea Spiru Haret 18(3), 109-122.

Statistica.com. (2020). Share of travel \& tourism users in the Philippines in 2020, by gender. Statista.com https://www.statista.com/forecasts/1201633/travel-tourism-users-philippines-by-gender

STR, (2021, Mar 30). Trend Report. STR. Trend \# 1253206_SIN. Excel Report

UNWTO. (n.d). Tourism and Covid-19 - Unprecedented Economic Impacts. UNWTO.org. https://www.unwto.org/tourism-and-covid-19-unprecedented-economic-impacts

Vogels, E. (2019). Millennials stand out for their technology use, but older generations also embrace digital life. Pew Research.org. https://www.pewresearch.org/fact-tank/2019/09/09/us-generations-technology-use/

Zech, N.M. (2016). Crisis management within the hotel industry - A Stakeholder Relationship Management Approach. https://core.ac.uk/download/pdf/71807165.pdf

70 Consortia Academia Publishing (A Partner of Tourism Educators and Movers of the Philippines) 